\title{
Classes of Childhood Sexual Abuse and Women's Adult Couple Relationships
}

\author{
Bronwyn Watson, PhD \\ Griffith University \\ W. Kim Halford, PhD \\ The University of Queensland
}

\begin{abstract}
The current study assessed if childhood sexual abuse (CSA) can be meaningfully classified into classes, based on the assumption that abuse by a close family member differs in important ways from other abuse, and whether abuse classes were differentially associated with couple relationship problems. The childhood experiences and adult relationships of 1,335 Australian women (18-41 years) were assessed. Latent class analysis identified three classes of CSA: that perpetrated by a family member, friend, or stranger, which differed markedly on most aspects of the abuse. Family abuse was associated with the highest risk for adult relationship problems, with other classes of CSA having a significant but weaker association with adult relationship problems. CSA is heterogeneous with respect the longterm consequences for adult relationship functioning.
\end{abstract}

Keywords: family abuse; violence; marital separation; relationship satisfaction

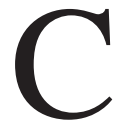

hild sexual abuse (CSA) of girls is common and associated with high rates of psychological disorder and other problems in adulthood (Beitchman et al., 1992). The association of CSA is particularly strong with problems in women's adult couple relationships. Compared to their nonabused peers, women with a history of CSA have double the rate of marital separation and are more dissatisfied with their relationships (Colman \& Spatz Widom, 2004; Fleming, Mullen, Sibthorpe, \& Bammer, 1999; Liang, Williams, $\&$ Siegel, 2006). Despite the strong association between CSA and adult relationship problems, many women with a history of CSA have stable and satisfying adult couple relationships (Colman \& Spatz Widom, 2004; Davis \& Petretic-Jackson, 2000). The variability in couple relationship problems of women with a history of CSA might be partially a function of the nature of the abuse experienced. The current study assessed whether CSA can be meaningfully classified into distinct classes and whether these classes are differentially associated with adult relationship problems.

\section{SIGNIFICANCE OF COUPLE RELATIONSHIP OUTCOMES ASSOCIATED WITH CHILD SEXUAL ABUSE}

Clarifying the association between CSA and couple relationship problems is important. Couple relationship distress and separation are common problems, which are strongly 
associated with elevated risk of psychiatric disorder in adult partners and their offspring (Whisman \& Uebelacker, 2006), reduced work productivity (Whisman \& Uebelacker, 2006), increased risk for poverty (Wilmonth \& Koso, 2002), and are very costly to society (Halford, Markman, \& Stanley, 2008). Clarifying the association between CSA and couple relationship problems could guide efforts to prevent or treat such problems.

There have been numerous attempts to refine the assessment of CSA beyond its presence or absence, and to relate aspects of abuse to adult relationship outcomes. These attempts to refine the assessment of CSA fall into three broad categories, discriminating abuse by the presence of a particular aspect of abuse (e.g., vaginal penetration), classifying abuse on a continuum of severity, and defining classes of abuse on the basis of multiple abuse characteristics.

With respect to classification of CSA based on a particular characteristic of the abuse, more extensive adult relationship problems are reliably associated with more physical intrusion by the perpetrator (i.e., vaginal penetration relative to genital touching relative to nongenital touching; Fergusson, Horwood, \& Lynskey, 1997; Fleming et al., 1999) and abuse perpetrated by a family member rather than a friend or a stranger (Noll, Trickett, \& Putnam, 2003). Greater use of psychological coercion by the perpetrator (Basta \& Peterson, 1990) and a lack of disclosure of the CSA by the victim (Jonzon \& Lindblad, 2004) are associated with more psychological impairment in women with a history of CSA, and might also predict adult relationship outcomes. However, inconsistent associations have been found between adult relationship outcomes and a range of other CSA characteristics including the age of the perpetrator (Cyr, Wright, McDuff, \& Perron, 2002), age of the victim, number of perpetrators involved in the CSA, duration of the abuse (Beitchman et al., 1992), and the use of physical violence by the perpetrator (Cyr, McDuff, \& Wright, 2006). These inconsistent findings, and the possibility that different abuse characteristics might moderate each other's effects (e.g., vaginal penetration during CSA might be particularly harmful if perpetrated by a close relative rather than a stranger) highlight the need to consider the effect of multiple aspects of abuse simultaneously.

CSA classified along a continuum of severity has been examined for its association with adult relationship outcomes, but there has been a lack of consensus about which CSA characteristics best define severity, and a lack of consistent association between indices of CSA severity and adult relationship outcomes (Fassler, Amodeo, Griffin, Clay, \& Ellis, 2005). Furthermore, assessed CSA seems to be distributed in a bimodal fashion, with a large proportion of women experiencing low severity and a substantial but smaller proportion experiencing high severity (Haugaard, 2000). This discontinuous distribution suggests that CSA might form distinct classes rather than falling on a continuum of severity.

Recent approaches to classifying CSA have used cluster analysis to define CSA classes and examine their association with adult outcomes. Some early studies had relatively small samples and did not reliably differentiate abuse clusters on aspects of their CSA experiences (Carlin \& Ward, 1992; Follette, Naugle, \& Follette, 1997). Four recent studies with larger samples identified different numbers (three to eight) classes of CSA (Alexander \& Schaeffer, 1994; Bennett, Hughes, \& Luke, 2000; Hulme \& Agrawal, 2004; Trickett, Noll, Reiffman, \& Putnam, 2001), but there was a consistent finding that a cluster of abuse characterized by invasive and coercive abuse perpetrated by a family member had worse adult psychological outcomes than other clusters. However, there are several limitations of these studies. Three of these studies used student or clinical samples (Bennett et al., 2000; Hulme \& Agrawal, 2004; Trickett et al., 2001), and two collected data only from women who had experienced incest (Alexander \& Schaeffer, 1994; Trickett et al., 2001). The lack of a broadly representative sample of women in these studies might have inadequately sampled 
the diversity of CSA. Moreover, only one study included a comparison group of nonabused women (Trickett et al., 2001), which made the interpretation of the extent of adjustment problems associated with CSA difficult. Finally, cluster analysis has been criticized because the criteria for defining classes produce unreliable results (Vermunt \& Magidson, 2000). Latent class analysis (LCA) has a similar objective to cluster analysis in seeking to classify individuals into groups, where group membership is unknown. However, LCA has the advantage that the criteria for class membership is reducing deviance on the indicator variables, and provides a more reliable assessment of the accuracy of model fit and classification into classes than cluster analysis (Vermunt \& Magidson, 2000).

\section{MODELS OF THE ASSOCIATION OF CHILD SEXUAL ABUSE WITH ADULT RELATIONSHIP OUTCOMES}

Several theoretical models of how the distal event of CSA impacts adult couple relationships suggest that CSA by a close family member is more harmful to the victim's later adult couple relationships than CSA by other perpetrators. For example, Alexander (1992) suggested CSA by family members is highly disruptive of the formation of secure attachment, and insecure attachment mediates the association of CSA with both adult psychological adjustment (Roche, Runtz, \& Hunter, 1999) and couple relationship problems (Godbout, Lussier, \& Sabourin, 2006). Leonard and Follette (2002) used the term emotional avoidance to describe how the experience of CSA associates negative emotions with sex and emotional intimacy, particularly when the perpetrator is emotionally close to the victim, which allegedly leads CSA victims to avoid committed relationships. This avoidance can take the form of avoiding relationships all together, or by having frequent brief sexual encounters with limited emotional intimacy. Consistent with these proposals, CSA victims collectively have been found to have high rates of insecure attachment (Alexander et al., 1998) and have frequent short-term sexual relationships (Leonard \& Follette, 2002; Noll et al., 2003). However, there has not been research establishing a specific relationship between CSA by a family member, as distinct from CSA perpetrated by other people, with insecure attachment or frequent casual sexual relationships.

The perpetration of CSA by a close family member covaries with characteristics of the CSA (Fleming, 1997; Najman, Dunne, Purdie, \& Coxeter, 2005; Testa, VanZile-Tamsen, \& Livingston, 2005). For example, CSA perpetrated by family members has a higher mean frequency and longer duration across time than that perpetrated by people outside the family (Fleming, 1997; Najman et al., 2005). This suggests that there might be classes of CSA that relate not only to the relationship of the perpetrator and victim, but also to covarying aspects of the abuse. These classes might relate to later outcomes.

In addition to the direct effects of CSA, families in which CSA occurs often have other dysfunction that can influence victims' long-term adult adjustment. Specifically, the familyof-origin of CSA victims have higher rates of parental divorce (Colman \& Spatz Widom, 2004); interparental aggression (Fergusson et al., 1997; Vigil, Geary, \& Byrd-Craven, 2005); parental alcohol and substance abuse (Nelson et al., 2002); child abuse (Black, Heyman, \& Smith-Slep, 2001); parental psychiatric problems, unemployment, and family poverty (Colman \& Spatz Widom, 2004; Drake \& Pandey, 1996; Fergusson et al., 1997; Paveza, 1988); and lower family cohesion (Weissmann-Wind \& Silvern, 1994) than families of nonabused peers. At least some of these forms of dysfunction are more evident in families in which CSA was perpetrated by a family member, rather than in families in which CSA 
was perpetrated by someone outside the family (Bennett et al., 2000; Dong et al., 2003; Hulme \& Agrawal, 2004). Therefore, we reasoned that classes of CSA partly defined by the perpetrator-victim relationship would likely covary with the extent of family-of-origin dysfunction.

\section{RESEARCH AIMS AND HYPOTHESES}

In summary, prior research suggests that CSA is heterogeneous in terms of the abuse experience, its co-variation with family-of-origin dysfunction, and its association with adult relationship problems. Prior attempts to classify CSA have not been optimal, and the association of CSA with adult relationship problems has not been adequately evaluated. In the current study, based on the research previously reviewed, four variables were used as indicators in an LCA to define classes of CSA: the relationship of the victim and perpetrator, the severity of the physical intrusiveness of the CSA act, the extent of coercion used in perpetrating the abuse, and whether the occurrence of CSA was disclosed to others. The current study tested the prediction that CSA of girls can be classified into meaningful classes, with a distinction between family-member-perpetrated and other-person-perpetrated CSA (Hypothesis 1). Second, it was predicted that a class of CSA perpetrated by family members would be associated with greater reported family-of-origin dysfunction than other classes of CSA, or with families of women not subjected to CSA (Hypothesis 2). Finally, it was predicted that a class of CSA perpetrated by a family member would be more strongly associated with adult couple relationship problems than other classes of CSA (Hypothesis 3).

\section{METHOD}

\section{Participants}

The current research was reviewed and approved by the Griffith University Human Research Ethics Committee. The Australian Electoral Commission provided the details of a randomly selected sample of 4,991 Australian women aged between 18 and 41 years. Registration to vote is compulsory for all people more than 18 years of age in Australia, and the electoral roll provides a reasonable approximation to the national adult population. The selected women were sent an invitation to participate in a study of "the effects of childhood experiences on women's adult relationships," a questionnaire, and a reply paid return envelope. We received 423 responses indicating the identified woman was no longer at the address, and 1,335 completed questionnaires (29.2\% of possibly received questionnaires). The mean age of the women who responded was 29.8 years ( $S D=6.7$ years). Table 1 presents the demographic characteristics of the sample and of all Australian women based on age-adjusted national 2001 census data (Australian Bureau of Statistics, 2001). Relative to the population of adult Australian women, the sample was similar on most socio-demographic characteristics except the sample overrepresented women with high levels of education.

\section{Measures}

Child Sexual Abuse. The Early Sexual Experiences Checklist (ESEC; Miller, Johnson, \& Johnson, 1991) lists 10 sexual incidents to which we added four items from Finkelhor's (1979) Survey of Childhood Experiences to provide a more complete list of possible 
TABLE 1. Demographic Characteristics of the Sample and Age-Adjusted Australian Women (2001)

\begin{tabular}{lcc}
\hline Characteristic & Sample $(\%)$ & Population $(\%)^{\mathrm{a}}$ \\
\hline Full-time employment & 42 & 35 \\
Part-time employment & 32 & 27 \\
Completed high school & 92 & 57 \\
Married & 40 & 43 \\
Cohabiting, not married & 21 & 12 \\
Born in Australia & 88 & 72 \\
Indigenous (self-classified) & 1 & 2 \\
Self-identifies with a religion & 79 & 86 \\
\hline
\end{tabular}

${ }^{a}$ Data from the Australian Bureau of Statistics.

unwanted sexual experiences. The respondent identified from the list any unwanted sexual experience they had at or before 16 years. Test-retest reliability of reports of unwanted childhood sexual experiences on the ESEC is high $(r=0.92)$, over a 1-month period. If more than one incident was reported, respondents indicted which incident bothered them the most. We classified the severity of the most bothersome incident as $1=$ noncontact, 2 = contact without penetration, 3 = vaginal penetration. . Respondents reported on their age when the most bothersome act first happened, the number and approximate ages(s) of the perpetrator(s), if the abuse occurred more than once, and over what duration the abuse continued. The frequency of abuse was classified as a single episode or occurred two or more times. We classified the relationship of the most closely related perpetrator to the woman as $1=$ stranger, $2=$ friend, $3=$ relative . Respondents reported if any of five different forms of psychological coercion (tried to talk you into it; scared you; said they would hurt you; said they would not love you; bribed you) or four types of physical force (pushed, hit or physically restrained; injured; threatened with a weapon; drugged or got drunk) were used during the CSA. Physical force was relatively rare (reported by only $14 \%$ of CSA victims), and so we focused on psychological coercion. The number of psychologically coercive behaviors used by the perpetrator was used as an index of coercion. Women rated the extent to which the abuse bothered them at the time it occurred, and currently bothers them, on a 7-point scale from $1=$ not at all to $7=$ extremely. Participants also indicated if they had ever spoken to anyone about the CSA, and if so, who. We anticipated that a mother would often be the person disclosed to, and asked if they had told their mother to rate how supportive she was at the time on a 4-point scale from $0=$ not at all to $3=$ very. We also asked if the women had ever sought professional help for the CSA experience, and if so, whether it was useful.

Family-of-Origin Dysfunction. Family-of-origin relationships were assessed by having participants rate their family-of-origin during childhood on the cohesion, expressiveness, and conflict subscales of the Family Environment Scale (FES; Moos \& Moos, 1994). The FES subscales of cohesion, expressiveness, and conflict each consist of nine true/false items, with higher scores indicating a stronger presence of each family dimension (Moos \& Moos, 1994). A family relationships quality index was computed from the FES by summing the cohesion, expressiveness, and reversed conflict subscales (Moos \& Moos, 1994). The FES has high internal consistency (Bischof, Stith, \& Whitney, 1995) and test-retest 
reliability (Moos \& Moos, 1994; McCray, King, \& Bailly, 2005), and reliably differentiates distressed and nondistressed families (Bischof et al., 1995).

A short 10-item version of the Parental Conflict Tactics Scale developed by Skuja and Halford (2004) was used to assess interparental aggression in the family-of-origin. Participants were asked to rate how often they witnessed their parents engaging in particular conflict behaviors using a 4-point Likert scale ranging from never to more than twice. Skuja and Halford (2004) developed this measure by selecting the most frequently endorsed items from each of the violence, verbal aggression, and reasoning scales of the Conflict Tactics Scale, and asking about mother and father and father to mother acts (e.g., "Did you ever see your Mother push, hit or slap your Father?").

The physical abuse and physical neglect subscales of the screening version of the Childhood Trauma Questionnaire (CTQ-SF; Bernstein et al., 2003) were used to assess child abuse and neglect in the family-of-origin. Items in the CTQ-SF are rated on a 5-point Likert scale ranging from never true to very often true, with higher scores indicating greater levels of abuse or neglect (Bernstein et al., 2003). The physical abuse subscale assesses bodily assaults on a child by a family member that posed a risk of, or resulted in, injury. The physical neglect subscale measures the failure of caretakers to fulfil a child's basic physical needs (e.g., "When I was growing up, my parents were too drunk or high to take care of my family") (Bernstein et al., 2003). The CTQ-SF scales have acceptable internal consistency (Rosenbaum \& Leisring, 2003), and reliably identify child abuse (Bernstein et al., 2003; Rosenbaum \& Leisring, 2003).

Women's Adult Relationships. Women were asked whether they had ever been in a relationship with a male partner for 6 months or longer, married, separated, or divorced, and if so how many times they had experienced each of these. Nine hundred eleven respondents reported that they were currently in a sexual relationship with a male partner that was of at least 6 months duration. These 911 women completed two questionnaires about their current relationship. The Abbreviated Dyadic Adjustment Scale (ADAS; Sharpley \& Rogers, 1984 ) is a 7-item measure of global relationship adjustment, with higher scores reflecting higher adjustment. The ADAS has good internal consistency $(\alpha=.82)$, and discriminates between: (a) married and separated couples, and (b) couples seeking therapy and community samples. The Satisfaction Scale (SS) of the Female Sexual Function Index (FSFI; Rosen et al., 2000) consists of three items assessing global sexual satisfaction in the past 4 weeks, with higher scores reflecting higher satisfaction. The SS scale has good internal consistency $(\alpha=.89)$ and test-retest reliability across 3 to 4 weeks $(r=.83)$.

\section{Procedure}

Potential participants received a number coded questionnaire and an information sheet on the study. The information sheet informed them that their responses would be confidential, and that no indentifying information would be retained once we had established from the return of the numbered questionnaire that they had returned the questionnaire (up to two reminder letters were sent to people that had not returned the questionnaire). The information sheet provided a Web page address to a project Web site that gave further details on the researchers and the project being conducted. Both the information and the Web page included the contact details of the researchers, and the university ethics officer, and there was a statement that they could contact any of these people if they had concerns about the conduct of the research. The information sheet and Web site also included the statement that some people might wish to seek psychological assistance with regard to issues 
assessed in the questionnaire, and listed the contact details of a series of counseling and support services available to victims of sexual abuse.

The researchers received 114 comments in written form on the returned questionnaires, via e-mail or by telephone from women that had been sent the questionnaires. Of these comments 103 were positive, expressing a general opinion that it was good to see such research being done $(n=78)$, or that the respondents had valued the chance to reflect on their experiences $(n=25)$. Eleven complaints were received, seven expressed objection that the electoral roll had been used to send them unsolicited questionnaires (under Australian law the use of the electoral roll to identify potential participants in medical research is permitted subject to the approval of medical research evaluation committee established by the Australian Electoral Commission). Two respondents objected to the content of the questions, particularly the questions about sexual behavior, and reported being offended when reading the questions. When we could respond to the women making the complaints (when they rang or e-mailed us, rather than making anonymous comments) we replied explaining the rationale for the study, and offering referrals for assistance as appropriate. We also reported all complaints received to the Griffith University ethics committee within two working days of them being received, and also explained the action we had taken. No complaints were made directly to the university ethics officer.

Participants were not paid for participation in the study. We informed all participants that a nontechnical report on the results of the research would be made available by being posted on the project Web site, which was provided on completion of the study.

\section{Statistical Analysis}

An LCA was performed to examine the existence and composition of CSA classes. LCA estimates three types of model parameters: (a) the size and prevalence of each latent class, (b) posterior probabilities that an individual belongs to each of the classes, and (c) conditional probabilities that individuals in a particular class endorse a specific indicator variable, using the maximum likelihood criterion. Cases are assigned to the class for which they have the highest posterior probability. Model fit in LCA using large sample sizes is assessed using parsimony indices, of which the most widely used is the Sample-Size Adjusted Bayesian Information Criterion (SBIC). The model with the lowest SBIC is considered to best represent the data (Vermunt \& Magidson, 2000). The association of abuse class membership with couple relationship problems was explored using ANOVA and chisquare analyses. Sixty-four women did not report their CSA status and their data were excluded, leaving 1,271 cases in the analyses.

\section{RESULTS}

\section{Characteristics of Child Sexual Abuse}

Five hundred sixty-nine participants ( $45 \%$ of the sample) reported experiencing at least one unwanted sexual incident by 16 years of age. The mean age for first occurrence of CSA was 11 years $(S D=3.6)$. There was great variability in the nature of CSA reported: intercourse occurred in $20 \%$ of cases, unwanted physical touch (e.g., fondling or oral sex) in 65\%, and noncontact acts (i.e., indecent exposure) in the remaining $15 \%$ of cases. Of all reports of CSA, $67 \%$ involved the use of psychological coercion, $8 \%$ the threat of violence, and $14 \%$ the use of physical force by the perpetrator. The women estimated the perpetrator's age as 
a mean of 28.4 years $(S D=15.6)$, an average of 17.5 years older than them at the time, though $33 \%$ of perpetrators were minors (17 years or younger). The majority ( $89 \%$ ) of victims knew their perpetrator; half of the perpetrators (55\%) were friends, and a third (34\%) were family members. Most women (86\%) reported only one perpetrator was involved in the CSA. Approximately half (47\%) of women were abused once, while $36 \%$ of women experienced CSA over an extended period of several months to a year or more. Half $(54 \%)$ of the women disclosed the abuse at the time it occurred; however, only $7 \%$ of women reported it to the police or other authorities. Most women (87\%) described the CSA to be moderately to extremely distressing at the time, and 51\% reported currently being moderately to extremely distressed by the CSA. Only $16 \%$ of CSA survivors sought professional help for the abuse, but of those who did $80 \%$ reported it to be useful.

\section{Classes of Child Sexual Abuse}

We classified CSA by conducting an LCA using Mplus (version 3; Muthen \& Muthen, 2005) on four indicator variables: relatedness of the victim and perpetrator, severity of the CSA act, use of psychological coercion by the perpetrator, and disclosure of the abuse. The SBIC was minimized with three classes of CSA. Table 2 presents the probability that individuals came from an assigned class, and descriptive data on each of the indicator variables used to define the classes. As is evident from Table 2, the classes are clearly distinguishable, and Table 3 shows the classes differed substantially on most abuse characteristics. For convenience we labeled the classes, the family, friend, and stranger abuse classes as the perpetrator-victim relatedness discriminated between the classes. In the family class all victims were abused by a family member, and small proportions of victims had also been abused by strangers or friends. In the friend abuse class all victims had been abused by friends, and a few by strangers as well. The stranger abuse class was characterized by abuse only by strangers.

Family abuse began early (with an average age of onset of 9 years); was physically invasive (with most cases involving genital touching and/or oral sex and in more than 1/4 of cases intercourse had occurred); was coercive (involving a range of forms of psychological coercion by the perpetrator including stating the victim wouldn't be loved if she did not comply); and was chronic (with $2 / 3$ of cases lasting at least several months). Women in the family abuse class were most often abused by older brothers and fathers. Few women disclosed the abuse; those that did were most likely to tell their mother, but those who informed their mother reported receiving little to no support from her. Women in the family abuse class reported high levels of distress regarding the abuse, both at the time it occurred and currently.

Friend abuse occurred later (with an average age of onset of 12 years); involved moderate levels of physical invasiveness (most cases involved the perpetrator touching the victim's genitals or other body parts); involved psychologically coercive actions by the perpetrator (such as talking the victim into going along with the act); and had a short duration (1/2 of all cases occurred only once). Two-thirds of these women were abused by young friends who were below 19 years of age; and most incidents only involved one perpetrator. Less than $1 / 2$ of the women disclosed the CSA; those that did were most likely to tell a friend about the abuse. Those women who told their mother about the abuse received a moderate level of support from her. Women in the friend abuse class reported high distress about the abuse when it occurred, but as adults $2 / 3$ reported no or minimal distress.

Stranger abuse occurred with an average age of onset of 12 years; involved low levels of physical invasiveness (approximately 3/4 of cases involved indecent exposure); involved low levels of psychological coercion (e.g., being intimated by the size of the perpetrator); 
TABLE 2. Probability of Membership and Abuse Characteristics by Class of Child Sexual Abuse

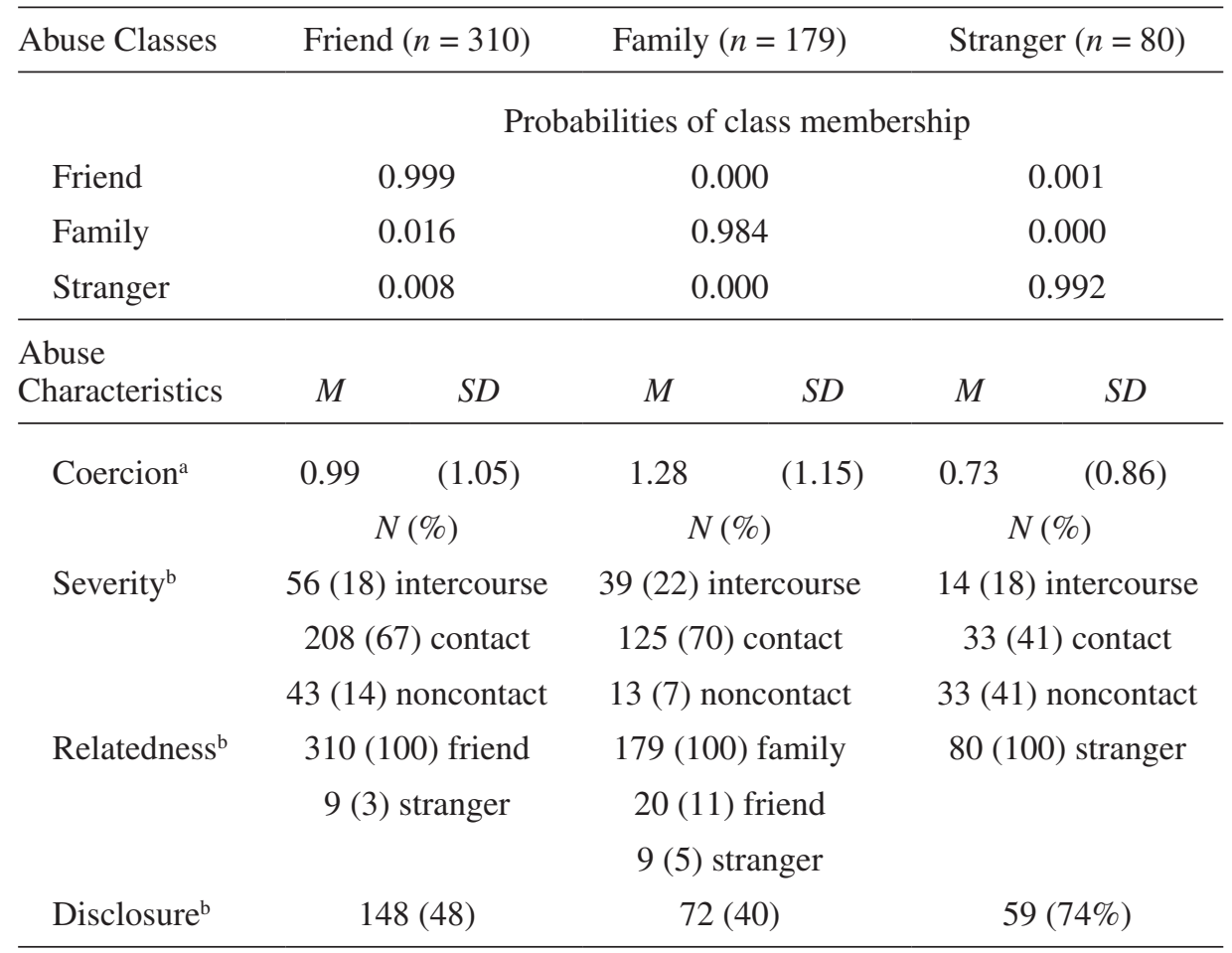

${ }^{a}$ Means and standard deviations (in parentheses) are presented for continuous variables.

${ }^{b}$ Number and percent (in parentheses) are presented for categorical data.

and typically occurred only once. Most women were abused by an unknown adult male with an average of 30 years, and multiple perpetrators were rare. Women often told a range of family members, friends, and other adults about the abuse; and those who told their mother received high levels of support from her. Women in the stranger abuse class reported high distress regarding the abuse when it occurred, but as adults reported little to no distress.

Table 4 presents the family-of-origin dysfunction by classes of CSA. Families of all classes of CSA were associated with higher rates of parental divorce, poorer family relationships, more interparental aggression, and more child abuse and neglect than families without CSA. As predicted, family dysfunction was particularly evident in the family abuse class. Relative to other classes of CSA, family CSA was associated with the highest rates of parental divorce, poor family relationships, and child abuse and neglect. There were not reliable differences between CSA classes on family-of-origin interparental aggression.

\section{Classes of Child Sexual Abuse and Adult Relationship Outcomes}

Table 5 presents data on women's relationship history and current functioning in each abuse class, and for nonabused women. Of the total sample of 1,271 women, $966(76 \%)$ reported they were currently in a heterosexual relationship; 185 women were dating partners, 272 women were cohabiting with a partner, and 509 were married. Of those not currently in an intimate relationship, $253(20 \%)$ were single and 46 (4\%) were separated or 


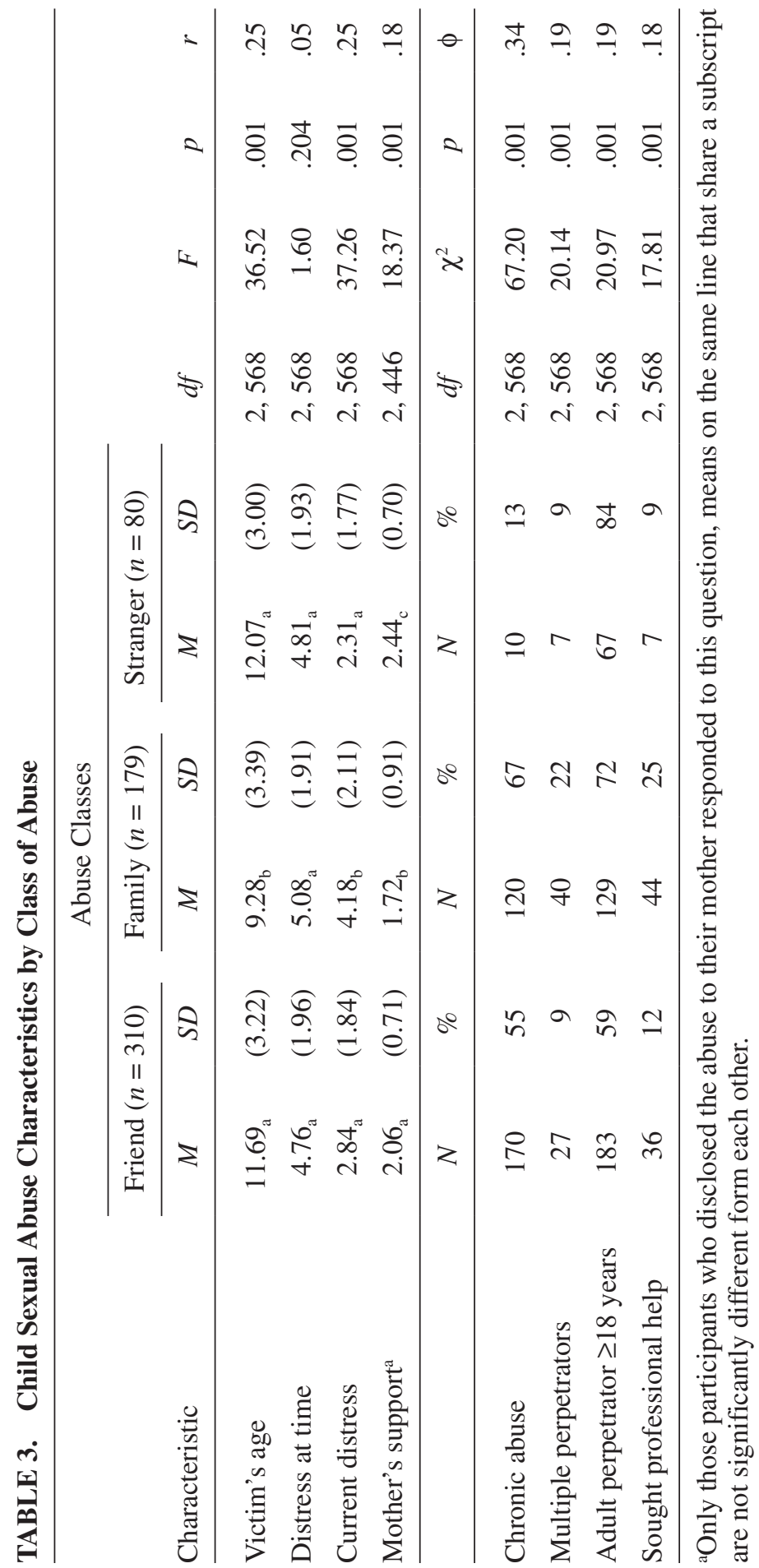









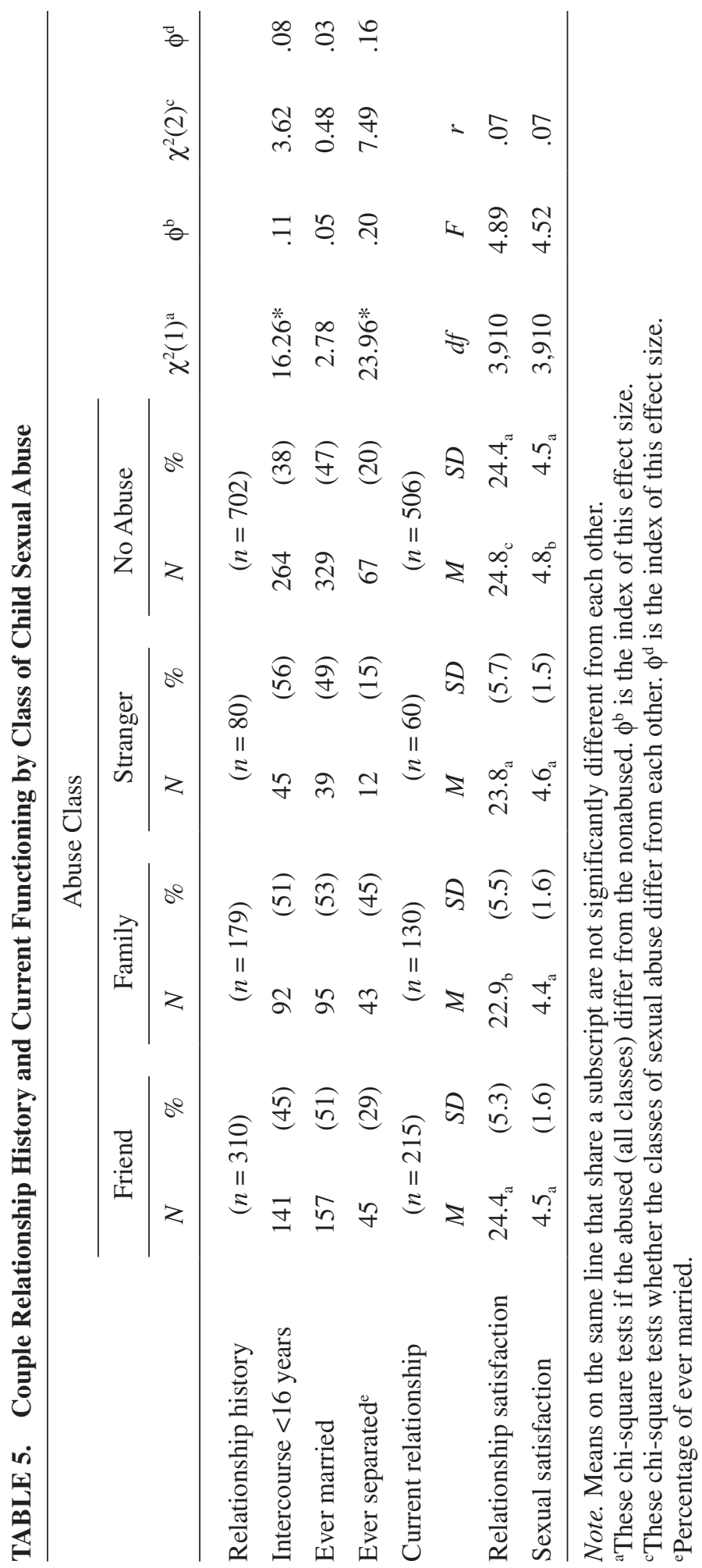


divorced. There were no differences between women with and without a history of CSA in the rates of cohabitation or marriage. However, CSA survivors were more likely to have begun consensual sex before age 16, been separated from a husband, and to report lower current relationship and sexual satisfaction than nonabused women. Women in the family abuse group were more likely to have separated from a husband, and reported lower current relationship satisfaction than other classes of CSA survivors.

\section{DISCUSSION}

The current research tested whether CSA can be classified into meaningful classes associated with the relatedness of perpetrator and victim, and whether the familyperpetrator class of CSA was more strongly associated with women's adult couple relationship functioning than other classes of CSA. Consistent with Hypothesis 1, CSA was separated into three distinct classes that differed on numerous abuse characteristics, and which could be differentiated on the basis of the perpetrator-victim relatedness. Hypothesis 2 received support in that any form of CSA was associated with a range of problems in reported family-of-origin functioning, but four of the five assessed aspects of dysfunction were most evident in the families-of-origin of victims of family CSA. Hypothesis 3 received partial support in that relative to nonabused women, women who experienced any CSA reported commencing consensual sex before age 16 more often and having more problems in adult heterosexual relationships. The victims of family CSA reported more marital separation and relationship dissatisfaction than the other abuse classes.

\section{Heterogeneity of Child Sexual Abuse}

The current study replicates prior research that CSA seems to fall into noncontinuous classes (Fassler et al., 2005; Haugaard, 2000), and extends that research in identifying three distinct classes of CSA. While the clearest discriminator between the classes was the relatedness of the perpetrator and victim, class also covaried with the severity of the sexual act, use of psychological coercion, and disclosure of the abuse. Family abuse had an early onset; was physically invasive, coercive, and chronic; was perpetrated by male family members; and was rarely disclosed and highly distressing. At the more extreme end of severity in this class one woman described being repeatedly raped by her father and brother across a period of 10 years commencing when she was just 8 years of age, and she described her childhood as a period of prolonged terror and intimidation. This CSA was never revealed to anyone at the time or subsequently. Friend and stranger abuse typically occurred in the prepubescent and early teenage years. Friend abuse was often perpetrated by peers or young adults, typically involved contact but not intercourse, and had a short duration. Stranger abuse typically was perpetrated by middle aged men, involved indecent exposure by the perpetrator, and was an isolated event.

The severity of couple relationship problems in the family abuse class identified in the current study is consistent with previous research that CSA perpetrated by family members is associated with higher rates of subsequent adult couple relationship difficulties than CSA perpetrated by other than family members (Noll et al., 2003). The current study extends prior work by suggesting that it is not only the relationship between the perpetrator and victim that is associated with the adult relationship difficulties of CSA survivors, but 
rather a cluster of distinct abuse characteristics and co-varying family-of-origin dysfunction which comprise family abuse.

In the current study the women who experienced any class of CSA had higher rates of couple relationship problems than nonabused women, and family abuse specifically was associated with the highest risk of marital separation and low relationship satisfaction. The magnitude of the association of CSA with low relationship satisfaction was small, showing there are still many women who experience CSA who develop satisfying adult couple relationships. At the same time, rates of marital separation were more than twice as high in family CSA victims as women not experiencing CSA. Given the high prevalence of CSA, these findings have substantial public health significance. Being in a mutually satisfying marriage is associated with lower rates of mental and physical health problems (Whisman \& Uebelacker, 2006), greater life expectancy (Burman \& Margolin, 1992), and fewer financial difficulties and less work absenteeism (Whisman \& Uebelacker, 2006). Relationship difficulties also have a substantial economic impact on the community (Halford et al., 2008). Therefore, being able to determine which CSA survivors are most likely to experience negative adult relationship outcomes, and seeking to assist them to have more satisfying and stable relationships, has substantial public health and economic implications.

Consistent with prior research (e.g., Mullen, Martin, Anderson, Romans, \& Herbison, 1996; Schloredt, \& Heiman, 2003), low sexual satisfaction in a current relationship was associated with experiencing CSA. However, the association was a small effect size, and there was no difference in sexual satisfaction between CSA classes. This highlights the fact that despite the experience of CSA, many of the women that were in relationships had normal sexual satisfaction.

\section{LIMITATIONS OF THE CURRENT STUDY}

The sample was self-selecting, and participants differed somewhat from a truly representative national sample. For example, people with low education were under-represented. A history of CSA might have made women more likely to volunteer for the study, which means that the prevalence rates might be an overestimate. Any sampling bias seems unlikely to distort the nature of the abuse classes, though it might influence the strength of association of those classes with couple relationship outcomes. For example, low education and social disadvantage are associated with a decreased likelihood of getting married (Lorenz, Simons, \& Chao, 1996), high rates of relationship distress, marital separation (Orbuch, Veroff, Hassan, \& Horrocks, 2002), domestic violence (Schumacher, FeldbauKohn, Smith-Slep, \& Heyman, 2001), and CSA (Anderson, Martin, Mullen, Romans, \& Herbison, 1993). Therefore, the current study that underrepresented women with low education, who are at high risk of relationship problems, might underestimate the association of CSA with poor relationship outcomes.

The sample size in the current study was large relative to most other studies of CSA, and provided adequate power to detect the observed small effect size differences between the family and friend abuse classes. However, there were no differences detected between the family and stranger abuse classes in terms of family-of-origin dysfunction or adult couple relationship functioning. This could mean that, despite the differences in the characteristics of CSA perpetrated within those classes, functionally the classes are similar. Alternatively, the relative infrequency of the stranger abuse class meant there was only moderate power 
to detect differences between the stranger and other abuse classes. Future research with an even larger sample could detect further differences in the relationship problems associated with the stranger versus other abuse classes. However, as the stranger abuse class is the least common class of CSA, this limitation is probably not crucial.

Another limitation of the current study was the use of retrospective reports to assess CSA and family-of-origin functioning. Retrospective reports of childhood experiences can be biased, though have quite high reliability provided the reports are of behaviorally specific actions, or are of high impact events, and the mode of questioning does not induce biases through repeated questioning, suggestion, or the presentation of misleading information (Goodman, Batterman-Faunce, Schaaf, \& Kenney, 2002). In the current study, we sought to meet these criteria in the questions we posed, but it is still possible that there were reporting biases. This was a particular risk in the retrospective reports of family relationships, which are likely to be influenced by participants' recall of CSA (Briere \& Elliott, 1993). Prospective longitudinal research circumvents many of these difficulties, but recruiting a representative sample of young girls to report on CSA experiences and retaining them in a study until they enter adult relationships is expensive and difficult.

The study was cross-sectional and cannot establish causal relationships between variables. The finding that all classes of CSA, and family CSA in particular, are associated with adult couple relationship problems does not show that CSA in general, or family CSA in particular, caused these negative outcomes. Both the current study and prior research find CSA is associated with multiple aspects of family-of-origin dysfunction like parental divorce, interparental violence, and child physical abuse. Family-of-origin dysfunction accounts for some, but not all, of the observed association between CSA and adult relationship outcomes (Colman \& Spatz Widom, 2004). However, attempts to partition out the relative contributions of CSA versus other family-of-origin dysfunction are problematic. CSA and other family-of-origin dysfunction are closely associated, likely influence each other, and might well be influenced by common risk factors, such as social disadvantage. Such close association and possible mutual influence make it questionable about the practicality or utility of attempting to separate out their influences. Future research exploring the mediators of the association of couple relationship problems with classes of abuse and other family-of-origin dysfunction could inform theoretical models of causality, and guide the development of interventions to ameliorate the effects of CSA on adult couple relationships.

The current study focused on CSA in girls rather than boys because this form of abuse is significantly more common in females and results in different outcomes for the different sexes (Beitchman et al., 1992). However, it would be useful to examine whether CSA is as heterogeneous for males as it is for females and whether the classes identified in the current study are relevant to male victims.

\section{CONCLUSION}

The results of this study replicate and extend prior research showing that CSA is a heterogeneous phenomenon. Family, friend, and stranger CSA were different in terms of the nature of the abuse, co-varying family-of-origin dysfunction, and the extent of adult relationship problems experienced by victims. While all classes of CSA were associated with negative outcomes, family CSA was associated with the most adult couple relationship problems. 


\section{REFERENCES}

Alexander, P. C. (1992). Application of attachment theory to the study of sexual abuse. Journal of Consulting and Clinical Psychology, 60, 185-195.

Alexander, P. C., Anderson, C. L., Brand, B., Schaeffer, C. M., Grelling, B. Z., \& Kretz, L. (1998). Adult attachment and longterm effects in survivors of incest. Child Abuse and Neglect, 22, 45-61.

Alexander, P. C., \& Schaeffer, C. M. (1994). A typology of incestuous families based on cluster analysis. Journal of Family Psychology, 8, 458-470.

Anderson, J. C., Martin, J. L., Mullen, P. E., Romans, S. E., \& Herbison, G. P. (1993). Prevalence of childhood sexual abuse in a community sample of women. Journal of the American Academy of Child and Adolescent Psychiatry, 32, 911-920.

Australian Bureau of Statistics. (2001). Census of population and housing. Canberra: Author.

Basta, S. M., \& Peterson, R. F. (1990). Perpetrator status and the personality characteristics of molested children. Child Abuse and Neglect, 14, 555-566.

Beitchman, J. H., Zucker, K. J., Hood, J. E., Da Costa, G., Akman, D., \& Cassavia, E. (1992). A review of the long-term effects of child sexual abuse. Child Abuse and Neglect, 16, 101-118.

Bennett, S. E., Hughes, H. M., \& Luke, D. A. (2000). Heterogeneity in patterns of child sexual abuse, family functioning, and long-term adjustment. Journal of Interpersonal Violence, 15, 134-157.

Bernstein, D. P., Stein, J. A., Newcomb, M. D., Walker, E., Pogge, D., Ahluvalia, T., et al. (2003). Development and validation of a brief screening version of the Childhood Trauma Questionnaire. Child Abuse and Neglect, 27, 169-190.

Bischof, G. P., Stith, S. M., \& Whitney, M. L. (1995). Family environments of adolescent sex offenders and other juvenile delinquents. Adolescence, 30, 157-170.

Black, D. A., Heyman, R. E., \& Smith-Slep, A. M. (2001). Risk factors for child sexual abuse. Aggression and Violent Behavior, 6, 203-229.

Briere, J., \& Elliott, D. M. (1993). Sexual abuse, family environment, and psychological symptoms: On the validity of statistical control. Journal of Consulting and Clinical Psychology, 61, 284-288.

Burman, B., \& Margolin, G. (1992). Analysis of the association between marital relationships and health problems: An interactional perspective. Psychological Bulletin, 112, 29-63.

Carlin, A. S., \& Ward, N. G. (1992). Subtypes of psychiatric inpatient women who have been sexually abused. Journal of Nervous and Mental Disease, 180, 392-397.

Colman, R. A., \& Spatz Widom, C. (2004). Childhood abuse and neglect and adult intimate relationships: A prospective study. Child Abuse and Neglect, 28, 1133-1151.

Cyr, M., McDuff, P., \& Wright, J. (2006). Prevalence and predictors of dating violence among adolescent female victims of child sexual abuse. Journal of Interpersonal Violence, 21, $1000-1017$.

Cyr, M., Wright, J., McDuff, P., \& Perron, A. (2002). Intrafamilial sexual abuse: Brother-sister incest does not differ from father-daughter and stepfather-stepdaughter incest. Child Abuse and Neglect, 26, 957-973.

Davis, J. L., \& Petretic-Jackson, P. A. (2000). The impact of child sexual abuse on adult interpersonal functioning: A review and synthesis of the empirical literature. Aggression and Violent Behavior, 5, 291-328.

Dong, M., Anda, R. F., Dube, S. R., Giles, W. H., \& Felitti, V. J. (2003). The relationship of exposure to childhood sexual abuse to other forms of abuse, neglect, and household dysfunction during childhood. Child Abuse and Neglect, 27, 625-639.

Drake, B., \& Pandey, S. (1996). Understanding the relationship between neighborhood poverty and specific types of child maltreatment. Child Abuse and Neglect, 20, 1003-1018.

Fassler, I. R., Amodeo, M., Griffin, M. L., Clay, C. M., \& Ellis, M. A. (2005). Predicting long-term outcomes for women sexually abused in childhood: Contribution of abuse severity versus family environment. Child Abuse and Neglect, 29, 269-284. 
Fergusson, D. M., Horwood, L. J., \& Lynskey, M. T. (1997). Childhood sexual abuse, adolescent sexual behaviours and sexual revictimisation. Child Abuse and Neglect, 21, 789-803.

Finkelhor, D. (1979). Sexually victimized children. New York: The Free Press.

Fleming, J. M. (1997). Prevalence of childhood sexual abuse in a community sample of Australian women. The Medical Journal of Australia, 166, 65-68.

Fleming, J., Mullen, P. E., Sibthorpe, B., \& Bammer, G. (1999). The long-term impact of childhood sexual abuse in Australian women. Child Abuse and Neglect, 23, 145-159.

Follette, W. C., Naugle, A. E., \& Follette, V. M. (1997). MMPI-2 profiles of adult women with child sexual abuse histories: Cluster-analytic findings. Journal of Consulting and Clinical Psychology, $65,858-866$.

Godbout, N., Lussier, Y., \& Sabourin, S. (2006). Early abuse experiences and subsequent gender differences in couple adjustment. Violence and Victims, 6, 744-760.

Goodman, G. S., Batterman-Faunce, J. M., Schaaf, J. M., \& Kenney, R. (2002). Nearly 4 years after the event: Children's eyewitness memory and adults' perceptions of children's accuracy. Child Abuse and Neglect, 26, 849-884.

Halford, W. K., Markman, H. J., \& Stanley, S. M. (2008). Strengthening couple relationships with education: Social policy and public health perspectives. Journal of Family Psychology, 22, 497-505.

Haugaard, J. J. (2000). The challenge of defining child sexual abuse. American Psychologist, 55, $1036-1039$.

Hulme, P. A., \& Agrawal, S. (2004). Patterns of childhood sexual abuse characteristics and their relationships to other childhood abuse and adult health. Journal of Interpersonal Violence, 19, 389-405.

Jonzon, E., \& Lindblad, F. (2004). Disclosure, reactions, and social support: Findings from a sample of adult victims of child sexual abuse. Child Maltreatment, 9, 190-200.

Leonard, L. M., \& Follette, V. M. (2002). Sexual functioning in women reporting a history of child sexual abuse: Review of the empirical literature and clinical implications. Annual Review of Sex Research, 13, 346-388.

Liang, B., Williams, L. M., \& Siegel, J. A. (2006). Relational outcomes of childhood sexual trauma in female survivors. Journal of Interpersonal Violence, 21, 42-57.

Lorenz, F. O., Simons, R. L., \& Chao, W. (1996). Family structure and mother's depression. In R. L. Simons (Ed.), Understanding differences between divorced and intact families: Stress, interaction, and child outcome (pp. 62-82). Thousand Oaks, CA: Sage.

McCray, J. A., King, A. R., \& Bailly, M. D. (2005). General versus gender-specific attributes of the psychology major. The Journal of General Psychology, 132, 139-150.

Miller, R. S., Johnson, J. A., \& Johnson, J. K. (1991). Assessing the prevalence of unwanted childhood sexual experiences. Journal of Psychology and Human Sexuality, 4, 43-54.

Moos, R., \& Moos, B. (1994). Family Environment Scale manual (3rd ed.). Palo Alto, CA: Consulting Psychologists Press.

Mullen, P. E., Martin, J. L., Anderson, J. C., Romans, S. E., \& Herbison, G. P. (1996). The long-term impact of the physical, emotional, and sexual abuse of children: A community study. Child Abuse and Neglect, 20, 7-21.

Muthen, L. K., \& Muthen, B. O. (2005). Mplus: Statistical analysis with latent variables. User's guide. Los Angeles: Muthen \& Muthen.

Najman, J. M., Dunne, M. P., Purdie, D. M., Boyle, F. M., \& Coxeter, P. D. (2005). Sexual abuse in childhood and sexual dysfunction in adulthood: An Australian population-based study. Archives of Sexual Behavior, 34, 517-526.

Nelson, E. C., Heath, A. C., Madden, P. A. F., Cooper, M. L., Dinwiddle, S. H., Bucholz, K. K., et al. (2002). Association between self-reported childhood sexual abuse and adverse psychosocial outcomes: Results from a twin study. Archives of General Psychiatry, 59, 139-145.

Noll, J. G., Trickett, P. K., \& Putnam, F. W. (2003). A prospective investigation of the impact of childhood sexual abuse on the development of sexuality. Journal of Consulting and Clinical Psychology, 71, 575-586. 
Orbuch, T. L., Veroff, J., Hassan, H., \& Horrocks, J. (2002). Who will divorce: A 14-year longitudinal study of black couples and white couples. Journal of Social and Personal Relationships, $19,179-202$.

Paveza, G. J. (1988). Risk factors in father-daughter sexual abuse: a case control study. Journal of Interpersonal Violence, 3, 290-306.

Roche, D. N., Runtz, D. N., \& Hunter, M. A. (1999). Adult attachment. Journal of Interpersonal Violence, 14, 184-207.

Rosen, R. C., Brown, C., Heiman, J. R., Leiblum, S. R., Meston, C. M., Shabsigh, R., et al. (2000). The Female Sexual Function Index (FSFI): A multidimensional self-report instrument for the assessment of female sexual function. Journal of Sex and Marital Therapy, 26, 191-208.

Rosenbaum, A., \& Leisring, P. A. (2003). Beyond power and control: Towards an understanding of partner abusive men. Journal of Comparative Family Studies, 34, 7-18.

Schloredt, K. A., \& Heiman, J. R. (2003). Perceptions of sexuality as related to sexual functioning and sexual risk in women with different types of childhood abuse histories. Journal of Traumatic Stress, 16, 275-284.

Schumacher, J. A., Feldbau-Kohn, S., Smith-Slep, A. M., \& Heyman, R. E. (2001). Risk factors for male-to-female partner physical abuse. Aggression and Violent Behavior, 6, 281-352.

Sharpley, C. F., \& Rogers, H. J. (1984). Preliminary validation of the Abbreviated Spanier Dyadic Adjustment Scale: Some psychometric data regarding a screening test of marital adjustment. Educational and Psychological Measurement, 4, 1045-1049.

Skuja, K., \& Halford, W. K. (2004). Repeating the errors of our parents? Parental violence in men's family of origin and conflict management in dating couples. Journal of Interpersonal Violence, $19,623-638$.

Testa, M., VanZile-Tamsen, C., \& Livingston, J. A. (2005). Childhood sexual abuse, relationship satisfaction, and sexual risk taking in a community sample of women. Journal of Consulting and Clinical Psychology, 73, 1116-1124.

Trickett, P. K., Noll, J. G., Reiffman, A., \& Putnam, F. W. (2001). Variants of intrafamilial sexual abuse experience: Implications for short- and long-term development. Development and Psychopathology, 13, 1001-1019.

Vermunt, J. K., \& Magidson, J. (2000). Latent class cluster analysis. In J. A. Hagenaars \& A. L. McCutcheon (Eds.), Applied latent class analysis (pp. 89-106). Cambridge, MA: Cambridge University Press.

Vigil, J. M., Geary, D. C., \& Byrd-Craven, J. (2005). A life history assessment of early childhood sexual abuse in women. Developmental Psychology, 41, 553-561.

Weissmann-Wind, T., \& Silvern, L. (1994). Parenting and family stress as mediators of the long-term effects of child abuse. Child Abuse and Neglect, 18, 439-453.

Whisman, M. A., \& Uebelacker, L. A. (2006). Impairment and distress associated with relationship discord in a national sample of married or cohabiting adults. Journal of Family Psychology, 20, 369-377.

Wilmonth, J., \& Koso, G. (2002). Does marital history matter? Marital status and wealth outcomes among preretirement adults. Journal of Marriage and the Family, 64, 254-269.

Acknowledgments. The conduct of this research was partially funded by a scholarship from Griffith University Psychological Health Research Centre awarded to the first author. We thank Charles Farrugia, Jemima Petch, Claire Hitchings, and Vivian Jarrett for their feedback on earlier drafts of this manuscript.

Correspondence regarding this article should be directed to W. Kim Halford, $\mathrm{PhD}$, School of Psychology, The University of Queensland, St. Lucai QLD 4072, Australia. E-mail: K.Halford@psy.uq.edu.au 